\title{
The Pharmacist's Missing Role in the COVID-19 Pandemic
}

Salam W. Ahjel, BS Pharm, MS, PhD, PEBC ${ }^{1}$; Ali Azeez Al-Jumaili, BS Pharm, MS, MPH, PhD ${ }^{2}$

${ }^{1}$ Pharmacy Department, Al-Zahrawi University College- Kerbala, Iraq;

${ }^{2}$ The University of Iowa College of Pharmacy, Iowa, USA; University of Baghdad College of Pharmacy, Baghdad, Iraq

\section{Abstract}

Coronavirus disease 2019 (COVID-19) is an infectious disease caused by severe acute respiratory syndrome coronavirus-2 (SARS-CoV2). In Wuhan, China, the disease was first identified in December 2019 and has since spread globally, resulting in the ongoing 2019-20 coronavirus pandemic. Several countries across the world are facing a shortage in frontline providers, while pharmacists are asked to cut working hours during this pandemic fight. Pharmacists as healthcare professionals could contribute in many aspects as responders to this pandemic worldwide if they had expanded education, training, and scope of practice.

Keywords: COVID-19, Pharmacist Role, Pharmaceutical Education, Post COVID-19 Era, Frontline fighters

\section{Introduction}

On March 12, 2020, the World Health Organization (WHO) declared COVID-19 a pandemic ${ }^{1}$. Since its emergence from the Wuhan province of China in late 2019, Severe Acute Respiratory Syndrome Coronavirus 2 (SARS-CoV-2), was identified as the virus responsible for the coronavirus disease 2019 (COVID-19) respiratory illness. Additionally, COVID-19 has claimed the lives of $>290,000$ individuals worldwide and in the U.S more than 81,800 individuals as of May $12,2020^{2}$. Evidence suggests that there will be increases in these numbers until the world can find a vaccine. Additionally, there is a possibility that new strains of this virus may evolve.

This viral enemy is considered the new health care system challenge worldwide and could be the major cause of death for $2020^{3}$. Until a few months ago, infectious diseases as the main cause of mortality was an after-thought with the new major challenges consisting of cancers and chronic diseases. However, COVID-19 changed this, and we are facing high mortalities due to an infectious disease again. This challenge needs all of the efforts and talents of the health care sector. In Italy, Spain, France and the U.S retired medical staff are being asked to go back to work and new visa facilitations are in place for physicians and other well-trained and experienced frontline COVID-19 fighters ${ }^{4,5}$.

In contrast, some pharmacists currently are looking for a job, asked to stay home, or have had their working hours cut in this tough time 6 . Globally many healthcare authorities have purchased new ventilators and other respiratory monitors, but they do not have enough trained practitioners who can operate them. We propose that pharmacists worldwide can play vital roles in help fighting COVID-19 or other coming pandemics in many practice settings. In addition to pharmacists' role in

Corresponding author: Ali Al-Jumaili, BS Pharm, MS, MPH, PhD Adjunct Assistant Professor

The University of lowa | College of Pharmacy, lowa City, IA, USA Email: aliazeezali-aljumaili@uiowa.edu patient education and medication therapy management for chronic disease management, they are very well prepared administering vaccines. Although there is currently no vaccine for COVID-19, significant research is underway to develop a vaccine $^{7}$. When a vaccine does become available, it is likely that there will be high demand for access to the vaccine and a significant public health interest in achieving high levels of immunization in the community. Research shows that when pharmacists are empowered, as in Canada and the U.S., to provide immunizations, they substantially increase the number of vaccinated patients in the community ${ }^{8,9}$.

Pharmacists are the most accessible healthcare providers and the most common touch point for many patients within the healthcare system. In fact, $90 \%$ of all Americans live within five miles of a community pharmacy ${ }^{10}$. In rural and underserved communities and in areas experiencing physician shortages, pharmacists may be the only healthcare provider that is immediately accessible to patients. Pharmacists practicing in hospitals, clinics, physician offices, and community settings can treat infectious diseases, help patients, and save lives if they were well-trained. In hospital clinical pharmacy settings, pharmacists perform an excellent job through medication reviews and medication reconciliation upon admission and for transitions of care to critical care units.

In the post COVID-19 era, we have to expand our knowledge and practice. Moreover, pharmacy practice should be different in the post COVID-19 era by including pharmacists in many medical practices ranging from intravenous access to oxygen therapy, tracheal intubation, non-invasive ventilation, tracheostomy, cardiopulmonary resuscitation, bronchoscopy, and manual ventilation. Those practices can equip pharmacists well for future readiness ${ }^{11}$.

In addition, new courses and training programs can be developed to equip pharmacists to provide point-of-care testing (POCT) in close proximity to where the patient is receiving care. Rapid POCTs are available for use by healthcare providers to confirm infection in nontraditional testing sites 
such as pharmacy clinics, physician offices, and health department clinics $^{12}$. Rapid influenza diagnostic tests in pharmacy, for example, detect influenza within 15 minutes. This rapid diagnostic capability allows pharmacists to quickly initiate antiviral medication, if appropriate, and direct infected patients to more acute care settings.

In conclusion, we propose that pharmacists can increase the health care system's capacity for taking care of patients under conditions of uncertainty. Pharmacy practice will be different in the post COVID-19 era, with more pharmacists serving as frontline health care providers who help promote public health.

\section{Conflict of Interest: None}

\section{References}

1. WHO announces COVID-19 outbreak a pandemic https://www.who.int/emergencies/diseases/novelcoronavirus-2019

2. Coronavirus COVID-19 Global Cases by the Center for Systems Science and Engineering (CSSE) at Johns Hopkins University (JHU). Accessed on May 12, 2020. https://coronavirus.jhu.edu/map.html

3. Deaths from Covid-19. Here's how they compare to other causes of death https://www.statnews.com/2020/04/09/its-difficultto-grasp-the-projected-deaths-from-covid19-hereshow-they-compare-to-other-causes-of-death/

4. HHS watchdog finds severe hospital shortages in combating covid-19 https://www.washingtonpost.com/national/healthscience/hhs-watchdog-agency-finds-severe-hospitalshortages-in-combating-covid19/2020/04/06/2906af7e-7811-11ea-a130df573469f094_story.html.

5. The U.S. Department of State. Briefing With Senior State Department Officials On COVID-19: Updates on Health Impact and Assistance for American Citizens Abroad. Office of the Spokesperson. March 23, 2020. https://www.state.gov/briefing-with-senior-statedepartment-officials-on-covid-19-updates-on-healthimpact-and-assistance-for-american-citizens-abroad/
6. COVID-19 LATEST: Boots to temporarily close 60 pharmacies https://www.pharmaceutical-

journal.com/news-and-analysis/news-blog/covid-19latest-pharmacies-need-to-be-open-over-easterweekend-says-nhs-

england/20207843.article?firstPass=false

7. There Are No Vaccines or Medicines for COVID19, Yet https://www.fda.gov/news-events/pressannouncements/coronavirus-update-fda-and-ftcwarn-seven-companies-selling-fraudulent-productsclaim-treat-or

8. Government of Canada. Public Health Agency of Canada. Canadian Immunization Guide.https://www.canada.ca/en/publichealth/services/canadian-immunization-guide.html. (Accessed October 19, 2018).

9. Government of Canada. Public Health Agency of Canada. Canadian immunization guide chapter on influenza and statement on seasonal influenza vaccine for 2018-2019. May 2018. https://www.canada.ca/en/publichealth/services/publications/healthy-living/canadianimmunization-guide-statement-seasonal-influenzavaccine-2018-2019.html (Accessed October 22, 2018).

10. Centers for Disease Control and Prevention, "Advancing Team-Based Care Through Collaborative Practice Agreements" (2017) https://www.cdc.gov/dhdsp/pubs/docs/CPA-TeamBased-Care.pdf

11. Mikhael E M, Al-Jumaili A A. Can developing countries face novel coronavirus outbreak alone? The Iraqi situation. Public Health in Practice, Volume 1, November 2020,100004. https://doi.org/10.1016/j.puhip.2020.100004

12. Centers for Disease Control and Prevention, Influenza (Flu), Influenza Virus Testing Methods. www.cdc.gov/flu/professionals/diagnosis/tabletesting-methods.htm 